\title{
'Nearer to being characters in a book': how older people make sense of online communities and social networking sites
}

\begin{abstract}
This study looked at the relationship between local and online forms of community engagement for a small group of older people in the South of England. Interviews and a focus group were used to establish understandings of online community and social networking sites (SNS) within the context of existing relationships in local communities. Historical understandings of community influenced expectations for online community with four catalysts being identified which motivated engagement with community resources both online and locally. These were: 'spaces and places', family, roles and loss. There was a clear preference for meeting people face to face with online communities and SNS being used predominantly as tools for achieving this aim. Exploration of the catalysts offers ways that greater community involvement might be further facilitated through design initiatives. Suggestions include private 'family rooms', anonymous 'sharing spaces' and a focus on hyperlocal initiatives to connect local and online communities.
\end{abstract}

\section{Introduction}

The communal benefits of online communities and social networking sites (SNS) are now enjoyed by many Internet users, but remain of limited appeal to most older people [11]. Only $25 \%$ of those over 65 year olds now have an SNS profile in America [2] and this figure is even lower in the UK at 9\% [13]. Current concerns over social isolation and exclusion of the elderly in ageing societies suggest that communal resources like these will become increasingly important as societies age [6] so understanding older people's reluctance to engage with them is important. Previous research into older people's use of (elderspecific) online communities has shown them to be beneficial in terms of providing access to information, emotional support, fun and companionship with online peers $[18,19]$. More recent research focusing on older users of SNS (the most recent incarnation of online community) suggests that they are not so keen, often dismissing these forms of online social contact as irrelevant to their age group [11]. If they are used it is predominantly for maintaining passive connections with younger members of the family [10,12].

Research with younger users of Facebook has explored the relationship between use and social capital [14], a measure of the cooperative potential available through Facebook as a social resource. This research has shown an emerging trend for university students to use this SNS as a way of reinforcing pre-existing emotional bonds (bonding social capital) [5] as well as connect loosely with other new acquaintances (bridging social capital). Such uses may be particularly relevant to older users if they need to bolster local support because of declining mobility or reduced social opportunities. At present little is known about this offline to online dynamic for older users of SNS or online communities. Whilst similar effects have been shown for a broader Facebook demographic [3] such studies have not addressed older people specifically nor have they provided information about corresponding local (offline) contexts. In this study we consider how older users are involved in mapping their social relationships onto online communities and SNS from the baseline of local community involvement.

At the same time it should not be assumed that older people are necessarily aligned with the digital imperative of online community and SNS. In this study we acknowledge the significance of non-use [17] and consider understandings of 'community' prior to any online engagement, exploring motivations for use and non-use as part of our investigation.

Summarising, our research questions are as follows:

- How do older people's experiences and expectations of local community influence their attitude towards online communities?

- What motivations exist at a local community level for older people to engage with SNS and other forms of online community? 


\section{Methods}

This qualitative study sought to capture the experiences, motivations and preferences of a small group of older people with respect to SNS and online community, all of whom were living in the Meridian area on the south coast of England. A participatory approach was employed throughout, involving and consulting participants and community groups as part of the research process. Participants of retirement age were recruited through three different elder-specific community portals with a view to accessing participants with a diverse range of online and local community experiences. A deliberate attempt was made to recruit older participants with varying degrees of engagement with online community/SNS as well as those who had no online involvement at all. The community portals chosen included a local community organisation, a local computer club and an elderspecific online community based in the UK called DropBy. An initial survey with 43 respondents was used to identify a suitably diverse sample and this led on to fifteen individual interviews and a focus group. The final interviewees lived independently in their own homes and were aged between 65 to 87 years with a mean age of 73.4 years. There were nine women and six men. The semi-structured interviews took place in participants' homes and lasted approximately forty five minutes.

Analysis of interviews was conducted using an inductive process of thematic analysis. From this participants' understandings of 'community' and online community were ascertained and four 'catalysts' were identified which are used to explain underlying motivations for community engagement both locally and online. Participants' understandings of 'community' are first considered in order to address the first research question and then the four catalysts are used to frame a response to the second research question.

\section{Findings}

Our study was designed to investigate two key questions around understandings of 'community' and ongoing motivations for online and local community engagement. Here we address these questions directly using direct quotes from our participants to illustrate particular points. In order to protect participant confidentiality no real names are used.

\subsection{Understandings of Community}

For most of those interviewed, the blueprint for community had its roots in the family, with a suggestion that "real" community could only occur through extended family connections in a particular geographical location. This understanding was mostly historical and came through in childhood memories like Joanne's,

"being brought up in a small village, the sense of community there is tremendous actually and it can't be compared, I haven't been able to compare that with anything else, not really. Living there I had a huge family, I had cousins, six, seven cousins, you know, that sort of thing. But beside that one knew - and I was only a child and I felt I belonged there and I still feel that is where I really belong"

A significant part of this community feeling had been the experience of 'being known'. In childhood this had meant whole families knowing one another in a particular street or village. Now this was less common with family members often living some distance from one another in different areas of the country or abroad. None the less the possibility of 'being known' remained an important aspect of community feeling in the present. Two particular ingredients were seen as key to this: the opportunity to physically meet up with other people and there being a suitable number of people present. Physically meeting up and talking to people face to face was seen as an intrinsic part of generating a community feeling as Daphne explained in simple terms,

"community is where people meet up and socialise"

Despite the geographical dispersion of families all our participants were keen to emphasise the importance of this for maintaining family bonds. The same was true for involvement with local community groups. Community feeling was also seen as dependent upon a critical number of people being present in a particular place, as Carl explained,

"to me community it's gotta be small, it's containable"

The actual number was difficult to pin down but it was felt that having too many people could easily destroy feelings of belonging to a group. Overall our participants believed that their experience of community had changed irrevocably during their lifetimes (particularly with regards to family relocations) and would never return to the way it had been in the past. Perhaps understandably their views on 
community generally left them unconvinced about the possibilities for online community. The reasons given for this were that the Internet was too impersonal a medium for social contact to be emotionally satisfying. Given their emphasis on face to face meeting this was unsurprising. Some went as far as to say that onlineonly relationships were slightly unreal.

"They are nearer to being characters in a book... in the way that you relate to characters in a book, you relate to characters you know only via the internet" Iris

\subsection{Catalysts for Community Engagement}

Despite our participants' misgivings about local and online forms of community they were all involved in such endeavours to varying degrees. They maintained a pragmatic approach to everyday life and made use of social opportunities that were available to them. Here we consider what motivated them to engage with community resources and how they mapped local relationships online.

3.2.1. Spaces and Places. The nature of different physical and virtual spaces and places have a clear role to play in encouraging or discouraging community engagement. Sharing a geographical location was an obvious precursor to community involvement for this group of older people given their views on 'real' community. Our interviewees discussed many local places that acted as meeting points and catalysts for community engagement on an informal level. Almost all interviewees spoke about the importance of places such as pavements outside homes, parks, bus stops, local shops and doctors' surgeries in making connections with local people. In these places there was no guarantee of shared interests, but a likelihood of a shared experience of the physical neighbourhood and the routines associated with daily living in a certain place. As Iris explains in relation to her shopping excursions to the local shops,

"I may bump into one or two people I know but it's not very often these days. I think it depends on the time that we go shopping because I vary it, sometimes I go in the morning and sometimes I go in the afternoon but I do bump into some of the people I know and we stop and have a chat"

These places allow people to come together for the implicit sharing of life experience without an expectation of an enduring emotional connection and often formed the basis of 'being known' in a local community. In some cases these local spaces were a source of lasting friendships. In describing some of the important people in his life Bryan said the following,

"a lady and her husband opposite who I pick blackberries for and go and visit. I don't do just that for them. They do things for me and I do things for them, it's a reciprocal thing "

Local community centres were seen by many of our participants as the natural place to go if they wanted to make an explicit effort to meet people and get involved with 'community'. In this context participation focused on formal activities such as art classes or computer clubs with informal conversations taking place over coffee or lunch. Both forms of interaction were seen as important for communal feelings to take root. Many of our interviewees highlighted the importance of shared interests and activities for establishing friendships and community ties. Specific locations and contexts were seen as indicators of the likelihood of finding people who shared these things. Again the shared activity (such as classes) acted as a safe way of allowing the possibility of friendships to develop without there being pressure if this did not happen.

Some participants had also experienced community engagement through virtual spaces and places, including forums and SNS. Here the nature of shared space was defined differently, in terms of ideas and computer-mediated activities rather than the physicality of a setting. For some a shared focus of discussion was a sufficient motivation for online community engagement. Three of the men in our study engaged with Twitter for news, politics and current affairs. One of these men Carl was also a regular contributor and reader of the social news site Reddit, which he visited every day with the view that,

"there's a lot more like minded people online, especially on Reddit"

For other interviewees it was a shared interest in game playing that motivated them to engage with community online. Three of our female interviewees played social games through Facebook including online versions of Bingo and Scrabble. These games encourage social interaction to take place alongside gameplay using a separate text-based chat window. This allowed informal connections to develop alongside the game. Usually these games were played with people they already knew locally but not always. Marie played Bingo in a 'public room' and had developed a lasting friendship with someone that she had met whilst playing there. This developed into regular 
conversations via email with them meeting in person some months later.

In other cases gregariousness and enjoyable social interaction were all that was needed to frame the online space. This was particularly true of those involved with elder-specific online communities like DropBy. Daphne had developed a strong sense of belonging to a particular group of users that she had met on such forums. This group was made up of around 16 people who had first met on other forums some years earlier and had persisted as a group despite having to migrate to different sites a number of times. Interestingly Daphne described them as her 'local' forum even though its members were from all over the UK and abroad.

"Yeah, local online. Yeah, I shouldn't really use the word local should I really...they're scattered all over the country, because one of them's in Spain, he lives in Spain, but I don't, when I'm talking to it, I don't look at it that they're all over the country, we're just, sort of in a room together if you like...I think that I can honestly say that I'm closer to them than what I am my family" Daphne

What was interesting here was the way that the emotional closeness of the group members had been translated by Daphne into a physical closeness. This was unusual amongst our participants who were usually keen to transcend the online to local divide and meet people in person as much as possible and transform these online connections into 'real' ones. Daphne was also keen to meet these people in person but her chronic illness made travelling very difficult.

All of our interviewees who had joined DropBy did so in the hope of making or sustaining local connections. They expressed disappointment that other members of the community were so far away and indicated that they had hoped to make contact with more local people. Similarly much of the activity through Facebook extended local connections by engaging in interactions relating to real world spaces and places. Sometimes this was also set up as an online bridge to connect with local people online such as the Facebook group set up by Bryan for the film club that he ran at the local community centre.

3.2.2. Family. Family acted as an important conduit to community engagement both locally and online with family ties being the focus of everyday life for most of our interviewees irrespective of their geographical location. Those who were particularly active in their local communities were often physically and emotionally close to their immediate family, seeing them regularly and being involved in their day to day lives. This on-going contact provided opportunities for informal meetings with other local people who were friends and acquaintances of younger family members. Here Janet explains what happened when she moved to Newhaven to help support her grandchildren,

'I didn't like Newhaven, I didn't feel I belonged to it at all, it was only the children, and as a result of that all my acquaintances, friends like those two there, are my daughter's friends, not mine"

Regular contact with younger family provided more formal opportunities for community involvement through school and sports club activities. Family relationships were also at the core of engagement with SNS in the guise of Facebook. The preferences of family members with regards to particular communication technologies (e.g. mobile phones, texting, email, Skype, Facebook, etc.) were a strong motivating influence, determining the ongoing social practices of the family.

"I do email people. I thought, when I first got my laptop, this will be good to keep in touch with my family, but they don't really email. The younger ones do Facebook, even the older ones, one of my sons don't do Facebook, they don't do email, he doesn't phone either. I do think about Skype, maybe I could do that, but then again, if they're not doing it. If they're not going to be doing it, what's the point in me doing it?" Betty

Those with a close emotional connection to their family (irrespective of physical distance) were likely to use family-preferred routes for maintaining such connections, often taking the lead from younger members of the family. To this end many of our interviewees (twelve out of the fifteen) had joined Facebook in order to keep abreast of events in the lives of their younger family. For some interviewees this Facebook involvement was a predominantly passive viewing of family posts without comment, constituting a benevolent observation of their online lives as described by Betty,

"I am on Facebook. It's purely on the basis of seeing what my family are doing"

Engagement with Facebook was often accompanied by a sense of distaste at the triviality of exchanges and an awkwardness at 'overhearing' their family's private conversations in this public arena. Four interviewees specifically mentioned concern at seeing conversations 
involving their grandchildren that they felt they were not meant to see. Viewing Facebook rarely translated into active engagement with family or others in this online space and family posts of significance were more likely to prompt direct personal contact with that family member through an alternative (more private) means which usually meant the telephone.

Five of our participants had started to use Facebook in a more 'active' way, by posting their own content to the site. Three of these individuals had close relationships with family living nearby and used Facebook to augment their family and local community involvement. Facebook allowed them to maintain their family connections with a degree of independence, providing ways of expressing their family involvement without having to always be physically present. It also offered ways of extending their social network by getting to know the friends of their family before meeting them in person.

Family ties were not always central to these older people's lives and other social motivations did exist which were equally important. Indeed some of our interviewees had quite weak connections to their family and did not rely on them at all for a sense of ongoing involvement in life. Relationships beyond the family were sometimes perceived as peripheral but clearly had a part to play in maintaining the shape of everyday life, often taking place with peers and focused on shared regular activities and light-hearted companionship. This same emphasis was expressed in relation to local and online forms of community.

Communal activities and group membership with peers were important as they provided opportunities for shared meaningful activity and a source of regular companionship and the opportunity to make new friends. These relationships enabled a degree of independence from family allowing them to maintain their own sense of identity in the face of life changes. All of our interviewees were involved in group activities with their peers in one way or another and the nature of these groups was diverse. Overall there was an emphasis on shared endeavour but also fun and light-hearted companionship. There was an openness to meeting new people and starting new friendships.

Those of our participants who were online also took part in online communities. Their involvement with these communities was sometimes purely virtual, taking place through the 'open' global forums of the Internet which support anonymous participation; places like Twitter, Reddit and eBay where common interests are shared with other Internet users of all ages. Equally online communities were used to bridge the online and local worlds and make personal contact with peers for companionship and as sources of new friendship. The elder-specific online community, DropBy, was used in this way.

3.2.3. Roles. Roles are clearly important in terms of maintaining an ongoing sense of identity and purpose for older people post-retirement. All of our participants had taken on roles within local community groups ${ }^{1}$ like residents' associations, community centres, church and faith groups, children's after school groups, local charities, exercise classes, bowling clubs, art, knitting, tailoring, computing, lunch and travel groups. Many had assumed quite active roles in these groups such as trustee, treasurer, organiser, administrator, teacher or general helper as well as engaging as a user or beneficiary of other groups. Some of these roles also informed and motivated engagement with online communities.

Many of our participants assumed roles that made use of skills they had gained during their working lives such as Peggy's accounting skills for her role as treasurer or Ben's skills in computing and teaching for running the computer club. In other cases the volunteering roles made use of more general skills such as Peggy's driving for 'meals on wheels' or Marie's selling refreshments and making tea at her grandchildren's football club. What can be seen as common to all these roles is the importance of being able to make a useful contribution and to 'give something back' to their local communities. A number of our participants spoke in particular about the importance of feeling needed, and knowing that they made a contribution that no-one else could.

Whilst our participants might assume responsible roles in relation to certain community groups they were also quite happy to be users of other clubs, services or community centres. This ability to have varying degrees of responsibility in relation to voluntary roles was another feature of these older people's community engagement. This gave them flexibility in terms of how much they committed themselves to such roles over time, depending on availability and mobility. What may have started as a very active role in a community group would likely transform over the years into that of a passive user.

In comparison to the multitude of explicit local community roles, online communities and SNS did not

\footnotetext{
${ }^{1}$ This also represents a bias in our sample which was accessed via various community group memberships.
} 
offer our interviewees such well-defined roles. The only 'official' roles assumed online were those which extended local community responsibilities through the creation and administration of online groups. This practice was evident through the use of email lists, Facebook groups and groups within DropBy. Generally speaking online roles were more implicit than this, emerging as a result of stances taken during online interactions. The most common social role taken within SNS (Facebook) was that of the passive observer, as described here,

"I'm on Facebook, because my grandson can put his pictures on there, and his girlfriend can" Larry

Beyond this passive stance six of our interviewees had established roles based on fun and light-hearted engagement, posting jokes and humorous videos to online communities and playing word games with others through Facebook.

"I post stuff that I like you know...my basic aim in going online is, going anywhere, is to either be amused or to learn something so the other website that I probably spend more time on than DropBy is Reddit" Carl

The online roles of sharer, humorist and game player were emergent and implicit arising as a personal interpretation of online communities and SNS. There were very few formal roles within SNS and online communities. These social sites typically cater for the users or beneficiaries of the service without promoting specific roles that members can engage in. Using Facebook for instance does not involve any kind of stated role as part of community membership. Nor do elder specific online communities expect roles to be assumed as part of a member's enrolment or participation.

A few explicit roles did exist, such as moderators of online peer groups. Moderation was intended to ensure privacy and safety for group members. Here all new members were actively engaged in conversation from the beginning in order to assess their authenticity as prospective members and to make them feel welcome. Informal roles also emerged, such as being part of a 'welcoming committee' for new members, with other members joining in this activity. We saw similar behaviour with members of the Newhaven computer club but translating this behaviour directly from a local context to an online one appeared to be problematic. This behaviour was sometimes interpreted as unusual by some our interviewees who perceived it as an unexpected form of gatekeeping.
3.2.4. Loss. Loss is an inherent aspect of the ageing experience and present in the lives of all of our participants. It was perhaps most poignantly experienced through bereavement with the death of a spouse or close friend but other forms of loss were also apparent. The loss of significant roles in life and failing health and mobility were also common experiences in retirement which challenged individual autonomy and forced a reassessment of social relationships. The challenge of loss was often countered by greater involvement with community groups and activities particular those involving one's peers.

This affected the women in our study more than the men with five of our nine female participants having lost their husbands and none of the men having suffered similar bereavements. This caused these women to reflect upon having previously adopted a slightly insular life with their spouse, and a sense of not needing anyone else while they had each other. This had led to feelings of isolation after the loss of their spouse, and an eventual need to reach out and build new relationships with peers.

Loss was often accompanied by a heightened sense of loneliness and a feeling that the home was no longer a place of comfort in the same way it had been before. Some of those interviewed said that there was a point when they found being at home alone unbearable and had to get out and find somewhere else to be as Joanne explains,

"my husband died three years ago and I'd looked after him for a couple of years so I was more or less isolated at that time and I realised that I didn't want to stay at home and there are quite a number of ladies who have that; they don't like staying at home alone"

Involvement with community groups and activities helped assuage these feelings of loneliness and provided a new sense of purpose in life. Community groups and activities particularly those involving peers provided a degree of companionship and understanding which was not always possible elsewhere (even from family members). It was felt that sharing the experience of loss was sometimes easier with another older person who was more likely to have experienced similar losses as Larry explains,

"it is such a benefit, when your partner dies, and you can, if you want to, you can go down the bowls club, and see your friends, and they'll all help you over this, because most of them have been through it" 
Online community had a role to play here in connecting those with similar experiences of loss and allowing them to share the difficult emotions involved. Although less common, this same need for companionship and understanding was met through engagement with online communities. Daphne explains how she made a new friend through this kind of an online connection,

"I met her about four years ago on a widows forum. We both recently lost our husband and we just seemed to click somehow and we speak practically every day which is nice. It's just a shame that she's so far away" Daphne

Online forums are particularly useful when mobility or the lack of a local peer network are an issue. Those that specifically focus on bereavement make possible the job of sharing difficult emotions with others in a similar predicament.

Whilst not common, online community did have a part to play for two of our interviewees in helping them to deal with their loss by providing opportunities to share difficult emotions in sympathetic online forums. The physical presence of local community was more important in terms providing opportunities for shared meaningful activity rather than an overt sharing of emotion. Here SNS and online communities were used to establish new local community connections through the Internet but with an emphasis on face to face meeting as an ultimate objective.

\section{Discussion}

Online communities and SNS may have a part to play in helping older people maintain their community presence and avoid social isolation and loneliness. This study has shown the everyday significance of 'community' in older people's lives and has drawn out some of the reasons why they may choose to enlist online resources to support a feeling of community or not. Older people's appreciation of 'real' community comes from a time when shared geographical location and the presence of extended family were more common. Translating this into contemporary society found our group of older people showing a clear preference for meeting people face to face rather than online but an awareness that the Internet was already changing the social landscape. Engagement with online communities and SNS was still appreciated by our online participants but a sense of impersonal unreality remained which was sometimes difficult for them to resolve. This was particularly so when mobility was an issue and online family and friends were some distance away (as with Deidre's online 'local' forum). Face to face meetings were seen as an important (and often necessary) compliment to online interaction and our participants went to great lengths to meet face to face with online acquaintances. Our participants' use of Facebook appeared to show some similarities with student use in terms of supporting existing emotional bonds with family (bonding social capital) and to a lesser degree making new connections (bridging social capital) [5]. Elder specific online communities were more likely to provide this latter form of social capital. There were also important differences with younger users. Facebook connections with family were largely passive with our participants rarely interacting with family online. This questions any amplification effect on social capital beyond that which could be achieved through other passive media such as postcards or letters. In addition our older participants were keen to manage the gulf between bridging and bonding capital through face to face meeting as we saw with Marie's online Bingo friend. This perhaps suggests a greater expectation of intimacy from older users although further research would be needed to say for sure.

Our research also suggests that a better understanding of the four catalysts identified (family, roles, loss, spaces and places) is important if we are to provide better online support for older people within online communities and SNS. Here we reflect upon how the potential of these catalysts might best be tapped by future design of online communities/SNS.

\subsection{Family friendly SNS}

There are aspects of the design, administration and culture of SNS that do not encourage older people to actively engage with them and exclude them from family interactions that take place there. In particular the general lack of privacy and the triviality of public exchanges within Facebook were problematic for most of our participants. The general blurring of public/private boundaries and the expectations of personal disclosure within Facebook (and SNS) culture acted to negate family exchanges for many of our participants. Online spaces which supported a clear transition from public to private interactions were more conducive to growing intimacy (e.g. chat windows in Facebook games) and should be provided and made more accessible in SNS. The addition of a 'family room' to Facebook functionality would be of great benefit to older users where privacy could be ensured amongst family members.

Conversely public anonymity was seen as a beneficial aspect of the Internet that was missing from more 
closed environments like DropBy. The disinhibition associated with anonymous online interaction $[1,15]$ can allow emotions to be expressed in ways that may not happen with existing family and friends. The establishment of an anonymous 'sharing space' would be particularly important for those wishing to share the difficult emotions of loss that accompany ageing particularly bereavement.

\subsection{Online roles}

Most SNS and online communities do not encourage people to identify themselves through specific roles which can discourage older people's prolonged engagement. The significance of social roles in retirement has long been acknowledged as a significant part of healthy ageing [8] and underpins a great deal of government policy aimed at the older generation [16]. Roles were shown to motivate local community involvement by providing structured activity and a renewed sense of identity and purpose post retirement. There are few similar formal roles that exist within SNS and online communities and establishing these may be an important way of easing older people's integration into online communities. Such roles would have to support their active contribution to the community and make use of existing skills and experience.

Roles tend to emerge more implicitly online like the 'answer person' in a discussion forum [7]. In this study implicit roles emerged in the form of family observer as well as sharer, humorist and game player to the broader Internet audience. Some of these could form the basis of more formal roles within SNS and online communities as curators of family memories/genealogists, moderators of online discussions or online tournament organisers. The more explicit development of such roles could lead to greater engagement by some older users.

\subsection{Limiting online group size and 'being known'}

It was clear from our participants' accounts that group size was very important with regards to establishing a feeling of community. A number of our participants noted that when a community group got over a certain size something fundamentally changed for the worse. This emphasises the importance of 'being known' within a community where everybody is aware of everybody else's presence and knows their own particular qualities and skills. There are clearly limits to how many people can be known in this way and the feeling of 'togetherness' is therefore limited by the number of community members. This same principle seemed to reassert itself online with Daphne maintaining her 'local' online group feeling with sixteen others whilst many others expressed a lack of community feeling in relation to large communities like Reddit or Facebook. SNS by definition encourages a porous notion of community where the boundaries of friendship and family are blurred. Friends of friends and tangential group affiliations are all incorporated into representations of the group consciousness (e.g. Facebook timelines and Twitter feeds). This makes it impossible to have a feeling of knowing and 'being known' by all present. If SNS and online communities are to encourage older users' engagement they must first provide ways of restricting group membership appropriately and offer transparency with regards to who is privy to their online interactions.

\subsection{Hyper-local initiatives}

Access to local, face to face social interaction was still the litmus test for online community for our group of older people, mostly reinforcing local bonds and resulting in actual meetings. We found our participants using Facebook and DropBy as tools for maintaining and exploring local connections with disappointment being expressed by some interviewees that DropBy did not have as many local members as they had expected. We would suggest that this emphasis on hyperlocal [9] uses of social media is something that could be explored further with the older generation through the design of community initiatives which make use of the Internet to support local community interactions. Indeed DropBy itself is an online community that has started to pursue this approach by organising local lunch events for community members who live in a particular geographical location. Such local/online initiatives should be explored in further research.

\section{Conclusions}

SNS and other forms of online community have potential for ameliorating social isolation and loneliness amongst older people. In this study we have shown how some older users are making use of these opportunities to maintain their connections with family and friends as well as interact with strangers and develop new friendships. However it was clear that expressions of online community were still seen as impersonal and unreal unless accompanied by some face to face interaction. The four catalysts ('spaces and places', family, roles and loss) highlight aspects of everyday life that continue to motivate community engagement and that need to be addressed in order to 
create online communities that are more appropriate and interesting to older users. They invite a revised approach to online community which accommodates different understandings of community and norms of privacy. In this paper we have proposed a number of design interventions based upon our four catalysts which are intended to promote greater engagement within online community by older users.

In addition we acknowledge the concerns of our participants in relation to the 'digital imperative' that pervades post-industrial societies. For almost all of our interviewees there was clear resistance towards the online-only or "digital by default" [4] trends that exist in public discourse and emerging social norms. It should not be assumed that online community can by itself solve the problems of social isolation and loneliness amongst older people. As our participants reminded us it is the human aspect of community that is the resource rather than the technologies through which this is accessed.

\section{Acknowledgments}

We would like to thank all of our participants for taking part in the research particularly those from the Meridian Mature Citizen's Forum. We would also like to thank Kate Davies (MMCF), Bill Kocher (MMCF) and Mary Baker (DropBy) for their support in facilitating access to their members. This pilot study was funded by the RCUK Digital Economy Communities \& Culture Network+.

\section{References}

[1] Barak, A., Boniel-Nissim, M., \& Suler, J., Fostering empowerment in online support groups. Computers in Human Behavior, 24(5), 2008, 1867-1883.

[2] Brenner, J. and Smith, A., 72\% of Online Adults are Social Networking Site Users. Pew Internet and American Life Project, August 5, 2013. Available at: http://pewinternet.org/ /media//Files/Reports/2013/PIP_Soci al_networking_sites_update_PDF.pdf [Accessed May 8, 2014].

[3] Burke, M., Marlow, C., \& Lento, T. Social network activity and social well-being. In Proceedings of CHI 2010, ACM, 2010, pp.1902-1912.

[4] Cabinet Office, Government Digital Strategy, 2012. Available at: http://bit.ly/1guOabh [Accessed 10th February, 2014]

[5] Ellison, N. B., Steinfeld, C., \& Lampe, C., The benefits of Facebook 'Friends:' Social capital and college students' use of online social network sites. Journal of Computer-Mediated Communication, 12(4), 2007, article 1.

[6] European Commission, European i2010 initiative on eInclusion"To be part of the information society", 2007. http://ec.europa.eu/information_society/activities/einclusion/ docs/i2010_initiative/comm_native_com_2007_0694_f_en_a cte.pdf [Accessed 20th May 2014]

[7] Gleave, E., Welser, H. T., Lento, T. M., \& Smith, M. A., A conceptual and operational definition of 'social role' in online community. HICSS'09. 42nd Hawaii International Conference on InSystem Sciences, IEEE, 2009, pp. 1-11.

[8] Havighurst, R., J. and Albrecht, R., Older People. Longman, London, 1953.

[9] Hu, Y., Farnham, S. D., \& Monroy-Hernández, A., Whoo. ly: Facilitating information seeking for hyperlocal communities using social media. In Proceedings of the 2013 ACM annual conference on Human factors in computing systems, 2013, pp. 3481-3490. ACM.

[10] Karimi, A. and Neustaedter, C., My grandma uses facebook: Communication practices of older adults in an age of social media. Technical report, Simon Fraser University, 2011.

[11] Lehtinen, V., Näsänen, J., \& Sarvas, R. (2009). A little silly and empty-headed: older adults' understandings of social networking sites. In Proceedings of the 23rd British HCI Group Annual Conference on People and Computers: Celebrating People and Technology, British Computer Society, 2009, pp. 45-54.

[12] Nef, T., Ganea, R. L., Müri, R. M., \& Mosimann, U. P., Social networking sites and older users-a systematic review. International psychogeriatrics/IPA, 2013, pp.1-13.

[13] Ofcom, Adults' media use and attitudes report 2013. OFCOM, April 2013.

[14] Putnam, R. D., Bowling alone. Simon and Schuster, 2001.

[15] Selwyn, N., Apart from technology: understanding people's non-use of information and communication technologies in everyday life. Technology in society, 25(1), 2003, pp. 99-116.

[16] Suler, J., The online disinhibition effect. Cyberpsychology \& behavior,7(3), 2004, pp.321-326.

[17] World Health Organisation, Active Ageing: A Policy Framework, 2002. Available from: http://whqlibdoc.who.int/hq/2002/WHO_NMH_NPH_02.8.p df [Accessed 10th May, 2014]

[18] Wright K., Computer-mediated social support, older adults, and coping. Journal of Communication 50 (3), 2000, pp.100-18. 
[19] Xie, B., Multimodal Computer-Mediated Communication and Social Support among Older Chinese
Internet Users. Journal of Computer Mediated Communication, 13(3), 2008, pp.728-750. 